\title{
Retraction Note to: OSGA: genetic-based open-shop scheduling with consideration of machine maintenance in small and medium enterprises
}

\section{Shahaboddin Shamshirband ${ }^{1} \cdot$ Mohammad Shojafar $^{2}$.}

\section{A. A. Rahmani Hosseinabadi ${ }^{3}$ Maryam Kardgar $^{3}$ - M. H. N. Md. Nasir ${ }^{4}$.} Rodina Ahmad4

Published online: 27 November 2018

๑) Springer Science+Business Media, LLC, part of Springer Nature 2018

\section{Retraction Note to: Ann Oper Res (2015) 229:743-758 https://doi.org/10.1007/s10479-015-1855-z}

The Editor-in-Chief has retracted this article because validity of the content of this article cannot be verified. This article showed evidence of peer review and authorship manipulation. None of the co-authors agree to this retraction.

The original article can be found online at https://doi.org/10.1007/s10479-015-1855-z.

Shahaboddin Shamshirband shamshirband@um.edu.my

Mohammad Shojafar mohammad.shojafar@uniroma1.it

1 Department of Computer System and Technology, Faculty of Computer Science and Information Technology, University of Malaya, 50603 Kuala Lumpur, Malaysia

2 Department of Information Engineering Electronics and Telecommunications (DIET), Sapienza University of Rome, Via Eudossiana 18, 00184 Rome, Italy

3 Young Research Club, Behshahr Branch, Islamic Azad University, Behshahr, Iran

4 Department of Software Engineering, Faculty of Computer Science and Information Technology, University of Malaya (UM), 50603 Kuala Lumpur, Malaysia 